\title{
ESTUDO PONDERAL E BIOQUIMICO DE ALGUNS ORGÃOS DE RATAS SUBMETIDAS À DESNUTRIÇÃO PROTÉICA OU CALÓRICA, APÓS O DESMAME
}

\author{
Leda Ulson Mattos* \\ Mana Josefina Leuba Salum * \\ Maria Leonor Correa Pimentel Amaral
}

MATTOS, L.U.; SALUM, M.J.L.; AMARAL, M.L.C.P. - Estudo ponderal e bioquímico de alguns órgãos de ratas submetidas à desnutrição protéica ou calórica, após o desmame. Rev. Esc. Enf. USP, 9 (1): 35-47, 1975.

Os autores fizeram um estudo ponderal e hioquimico d' figado, haço, rim, coração e pancreas de ratas pertencentes a très grupos, cum peso médio de $48 \mathrm{~g}$, e que haviam sido alimentadas com três modelos experimentais de dietas, - balanceada. deficiente em proteinas ou em calorias -.. até atingirem o referido peso médio. Os animais dos modelos hipoprotéico $e$ hipocalórico ao atingirem o peso pré-estabelecido tinham 47 dias de idade $e$ os da dieta balanceada 26 dias. V'erificaram que as maiores alteraçōes no peso e no comportamento bioquimico dos órgãos ocorreram no figado e pâncreas dos animais com dieta hipoprotéica. Os órgäos dos animais que haviam sofrido restriçäo calórica não apresentaram diferenças $v$ gnificativas em relação aos dos animais considerados normais, com exceçä' do bą̧o que. embora aparentemente não tivesse sua composição alterada. perdeu peso.

\section{INTRODUÇÃO}

Em estudos nutricionais ou farmacológicos utilizam-se ani-

- Protessor Assistente Doutor das disciplinas Nutrição e Dietetica aplicadas à Enferma-

- Estudante de graduação da Escola de Enfermagem, bolsista da FAPESP.

*- Estudante de graduação da Escola de Enfermagem. 
mais normais, adultos ou cm fase de crescinento, para aferir o valor nutritivo de un alimențo ou a eficiencia terapèutica de um medicamento. Assim. o medicamento a ser testado a administrado em doses tomando como base o peso corporal do animal, aceitando-se que o critério peso do anmal seja suficiente para uniformizar as amostras, isto é, para torná-las homogèneas. Supōe-se que determinada droga administrada a animais escolhidos segundo o critério exposto, produza a mesina resposta terapéutica. No entanto, os paràmetros usados para avaliar a eficiència do material a ser testado, medicamento ou alimento, tais como aumento de peso, balanço nitrogenado e tempo de sobrevivência do animal, podem ser afetados por outros fatores não diretamente ligados ao peso (ROEDER \& (HOW, 1971 ).

ROEDER \& CHOW (1971) constataram que, em estudos nutricionais, o passado nutricional do animal pode ser potencialmente a causa das reaçōes anómalas que tornam irregulares os resultados dos experimentos.

Em nossos estudos também observamos que animais de mesmo peso, mas de diversas procedências comportam-se. muitas vezes, diferentemente quando submetidos ao mesmo tratamento dietético, em relação ao balanço nitrogenado, tempo de sobrevivéncia ou teste de crescimento.

Alguns autores estudaram as alterações metabólicas dos animais em relaçăo ao peso, à idade ou a ambos. BARROWS (1958) mostrou que a utilização da carne em lugar da caseína na dieta de ratos, aumenta o nivel da enzima colinesterase sem afetar o peso dos animais.

FUKUDA \& SIBATANI (1953) observaram que a restrição cilórica mantém o DNA celular do fígado a um nível correspondente ao scu peso corporal, ou melhor, um animal em restrição calórica mantém o DNA celular no mesmo nivel que um animal normal do mesmo peso. $O$ DNA total do figado aumenta com o peso corporal (CAMPBELL \& KOSTERLITZ, 1949). A velocidade com que aumenta o peso do animal, o peso do figado e o DNA no figado é linear (MENDES \& WATERLOW, 1958).

Por outro lado, animais nascidos de ratas desnutridas ou alimentados por ratas com dietas deshalanceadas são significativamente menores do yue us de màes bem nutridas (STEPHAN \& CHOW, 1968). Assim, uma população de animais de idade ou passado dietético desconhecido, pode 
incluir animais de crescimento deficiente que são cronologicamente mais vethos que os bem nutridos de mesmo peso. Alguns animais podem, peli aparência, facilmente serem distinguidos dos bem nutridos, mas em alguns casos isso não é possivel.

Se o número de a.umais utilizados nas experièncias fosse gran. de, estes anormais seriam provavelmente distribuídos entre os grupos. e não iriam afetar os resultados. Porém, sabemos que em virtude de limitações di recursos de trabalho, nem sempre é possível lidarmos com número grande de animais.

Os animais considerados normais podem ter sofrido um mi canismo de adaptação, considerando-se que os processos nutricionais desen cadeados pelos desequilibrios da nutrição são extremamente dinâmicos.

Estas considerações nos levaram à realização do presente tra balho, no qual estudamos alguns órgãos de ratas com peso corporal médio de $48 \mathrm{~g}$, que haviam atingido este peso através de tratamentos dietéticos diferentes. Esta pesquisa foi realizada em fêmeas, mas fizemos um estudo semelhante em machos (MATTOS e col., 1974).

Vários pesquisadores, estudando o comportamento ponderal e bioquímico de alguns órgãos de animais submetidos à desnutrição crônica ou ao jejum. encontraram diferenças significativas em determinados parâmetros estudados para avaliar não só em relação ao tratamento dietético que o animal recebia, mas também ao sexo do mesmo (WIDDOWSON \& McCANCE, HARRISON. 1953).

Submetemos os animais a três modelos experimentais de dieta, representativos de algumas condiçðes da nutrição humana, de maneira que estes resultados, dentro de certos limites, pudessem ser extrapolados para o homem.

Os modelos por nós utilizados foram:

$$
\begin{aligned}
& \text { Modelo I - halanceado } \\
& \text { Modelo II - deficiente em proteínas } \\
& \text { Modelo III - deficiente em calorias }
\end{aligned}
$$


Neste trabalho nos propusemos a:

1 - Estudar o comportamento ponderal do fígado, baço, rim, coração e pâncreas de ratas pertencentes a três grupos, com peso médio de $48 \mathrm{~g}$ e que haviam sido alimentadas com três modelos experimentais de dieta - balanceada, deficiente em proteínas ou deficiente em calorias - até atingirem o referido peso.

2 - Determinar o conteúdo de nitrogênio dos referidos órgãos, bem como os lipídeos totais e o conteúdo de água do fígado.

\section{MATERIAL E MÉTODOS}

\section{1 - Animais e dietas}

Animais: neste trabalho foram usados 30 animais (RATTUS NORWERGICUS, ALBINUS) Wistar, fêmeas, desmamados aos 21 dias e pesando em média $35 \mathrm{~g}$.

Dietas: na tabela (1) apresentamos as dietas utilizadas e as respectivas composiçð̃es.

\section{2 - Mctodos de dosagem}

2.1 - Dosagem de nitrogênio: foram feitas pelo método de Kjeldahl modificado (ALBANESE, 1963). Para determinar o nitrogênio nos orgãos usamos o órgão inteiro ou alíquotas, como no caso do fígado.

2.2 - Dosagem de lipídeos: dosamos os lipídeos totais no fígado pelo método de FOLCH e STANLEY (1956).

2.3 - Determinação da água: uma alíquota de fígado foi colocada na estufa a $1050 \mathrm{C}$ até que o peso se mantenha constante. A quantidade de água perdida é calculada. 

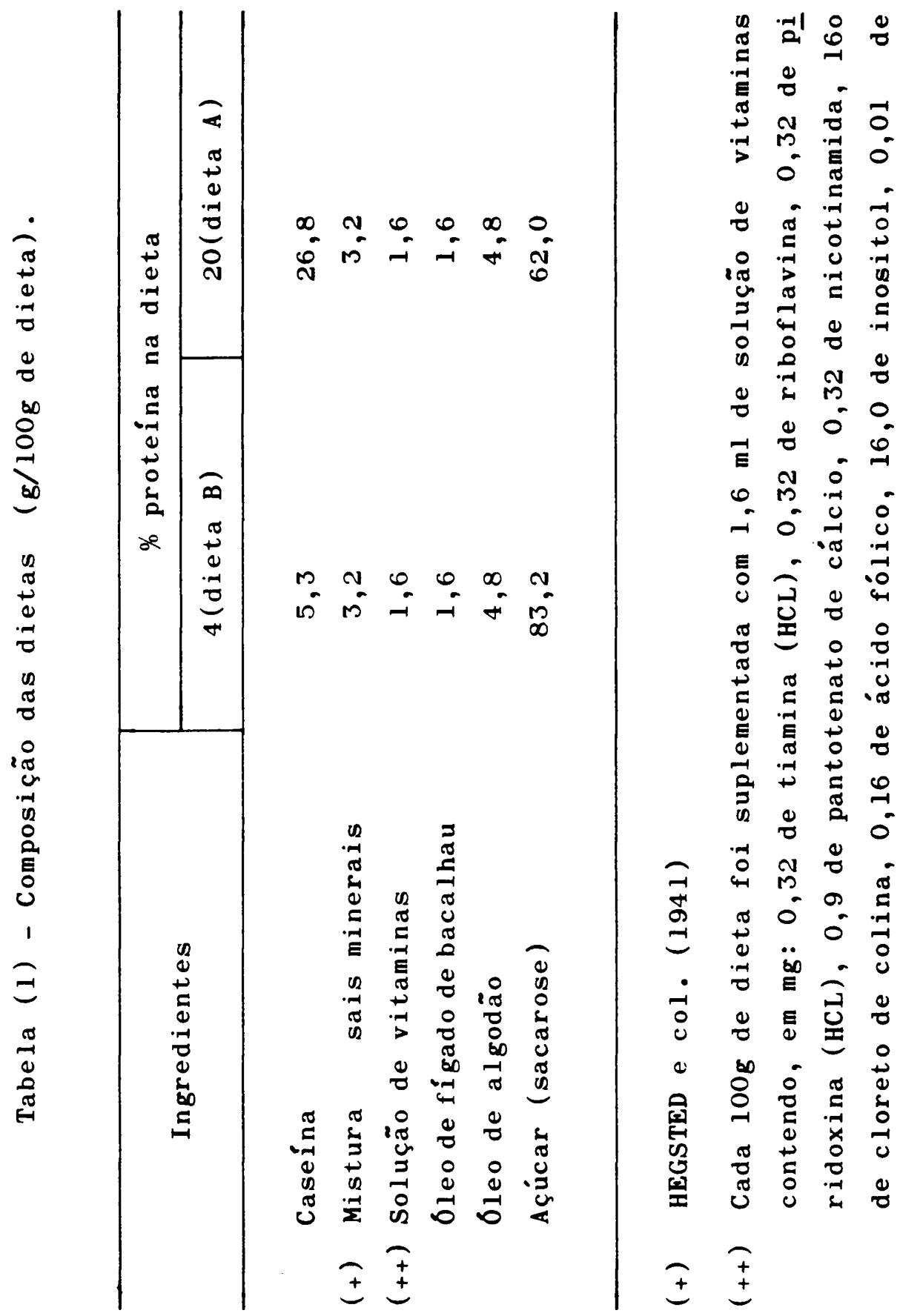

๑ मิ กิ

$\vec{E} \approx 00$

० $100-1$

$\begin{array}{llll}-1 & 0 & 0 \\ 0 & 0 & 0 & 0 \\ 0 & 0 & 0 & 0 \\ 0 & 0 & 0 & 0\end{array}$

ช 농 00

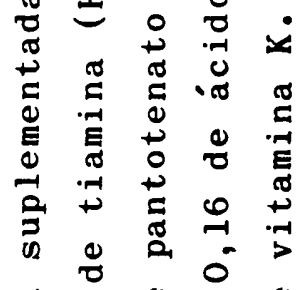

$=\ddot{0}$ में

హ)

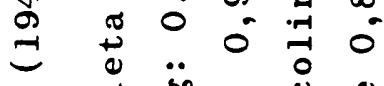

-

نำ

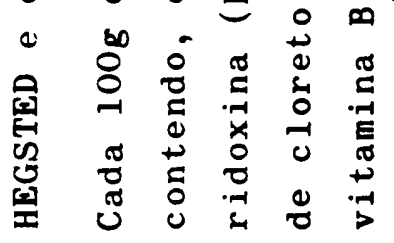

王 


\section{3 - Procedimentos experimentais}

As 30 ratas, de diferentes ninhadas, foram misturadas e distribuídas ao acaso em 3 grupos de 10, correspondentes aos três modelos experimentais:

Modelo I ou grupo controle: os animais deste grupo foran alimentados, ad libitum, com dieta $\mathrm{A}$, até atingirem o peso médio de $48 \mathrm{~g}$.

Modelo II: os animais foram submetidos à uma dieta hipoprotéica (dieta B) até atingirem o peso médio de $48 \mathrm{~g}$. A dieta foi fornecida ad libitum.

Modelo III: dez animais receberam a dieta $\mathrm{A}$, mas em quantidade determinada, de maneira que a curva de crescimento deste modelo acompanhasse a do modelo II.

Quando o peso médio dos animais de cada modelo atingiu $48 \mathrm{~g}$, os animais foram sacrificados pelo método de STEAD \& BROCK (1972) e os órgãos retirados e pesados. Foi feita a dosagem de nitrogênio do órgão inteiro, com exceção do fígado. Deste, foram tiradas três alíquotas: uma refrigerada a $15{ }^{\circ} \mathrm{C}$ para a determinação dos lipídeos e as duas outras usadas imediatamente para a dosagem da água e do nitrogênio.

\section{RESULTADOS E COMENTÁRIOS}

Os animais com dieta deficiente em proteína (Modelo II) e em calorias (Modelo III) levaram 26 dias para alcançar o peso médio de $48 \mathrm{~g}$. Por outro lado, os animais que receberam a dieta balanceada ou controle alcançaram este peso em 5 dias; assim, os animais tem o mesmo peso, mas os dos Modelos II e III são 21 dias mais velhos que os do Modelo I.

Pudemos observar pelos resultados da tabela (2) que, entre os animais dos Modelos I e II não houve diferença significativa, ao nível de $1 \%$, na ingestão de alimentos ou na caloria consumida.

Os animais do Modelo III ingeriram mais do dobro das proteínas e metade das calorias dos do Modelo II.

$\mathrm{Na}$ tabela (3) colocamos o peso corporal médio dos animais dos três modelos; peso médio dos órgãos estudados em gramas, e como porcentagem do peso corporal. 


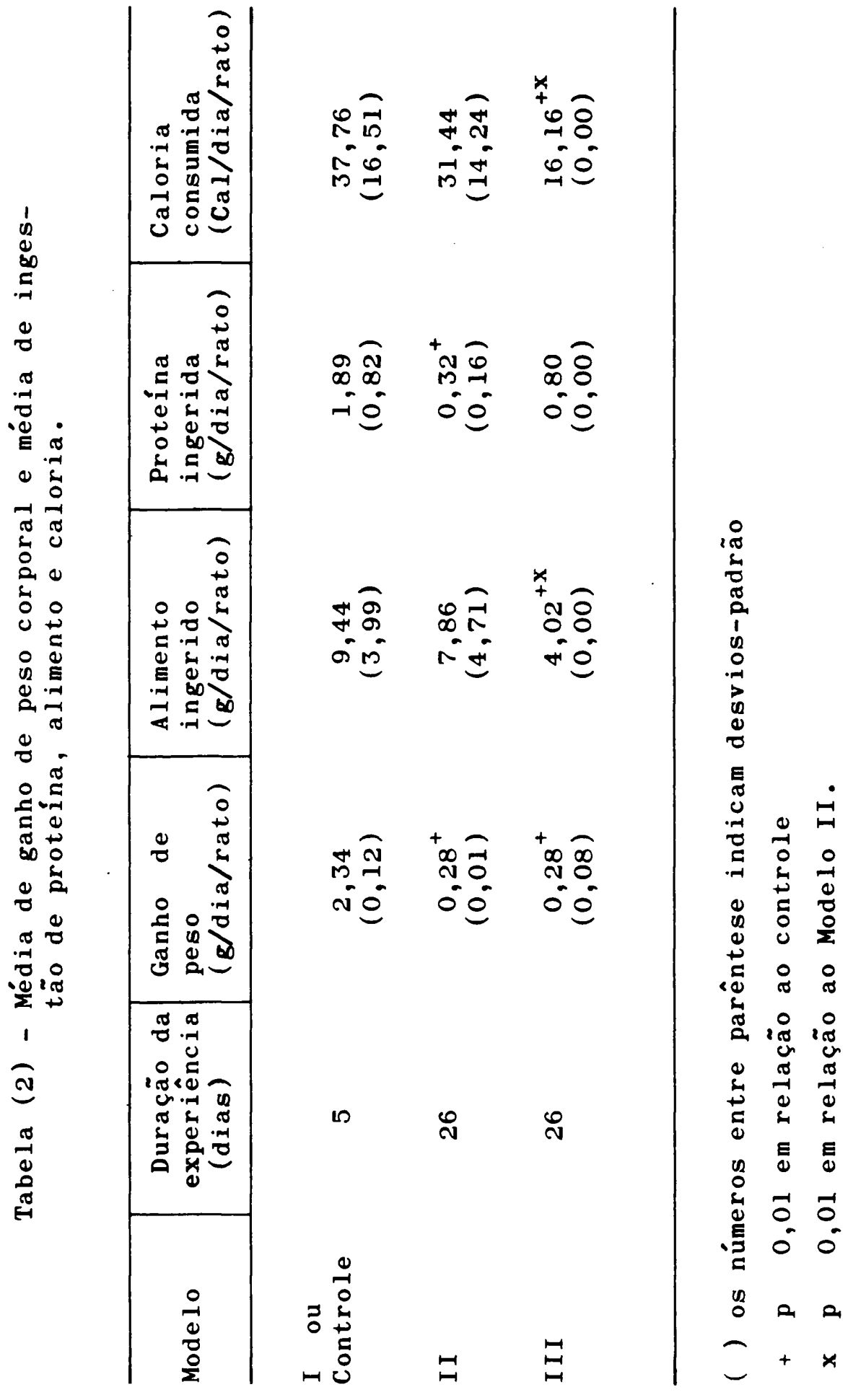




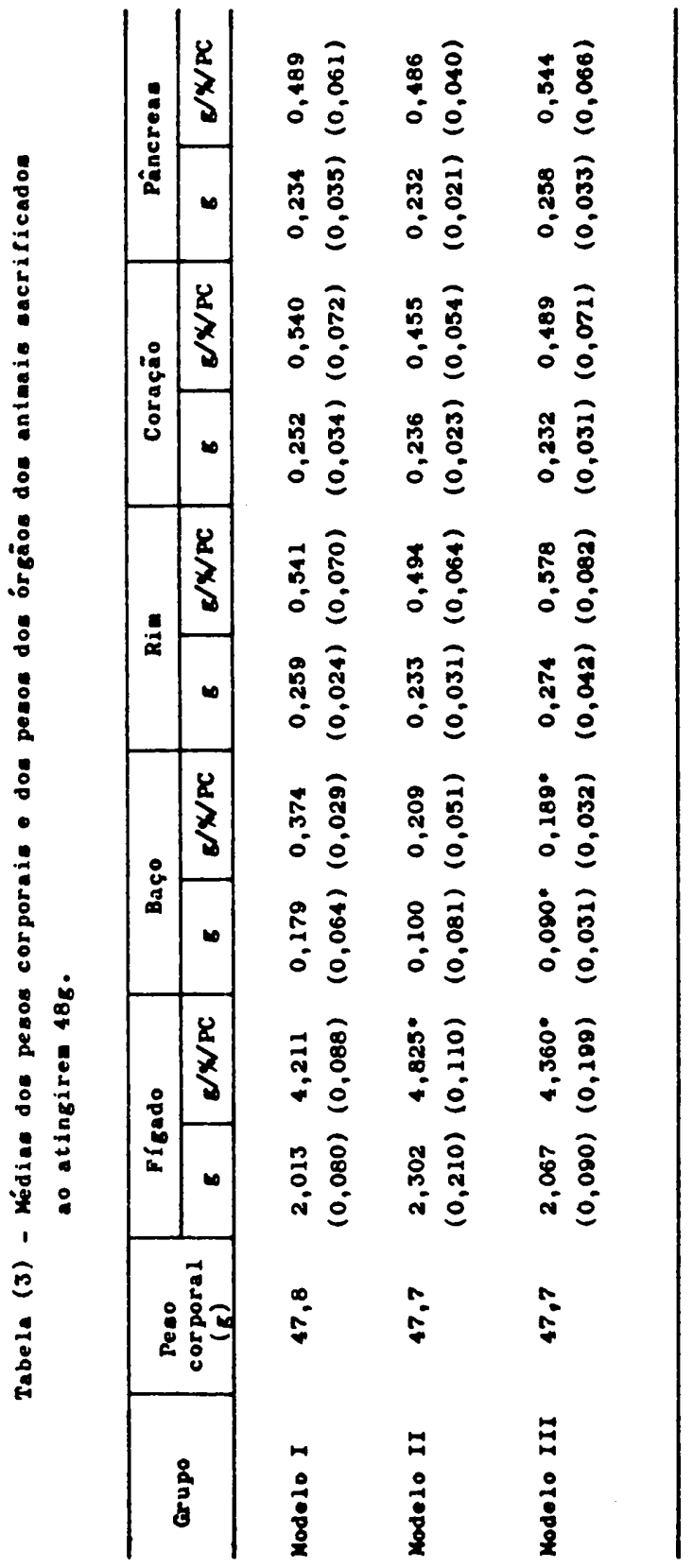




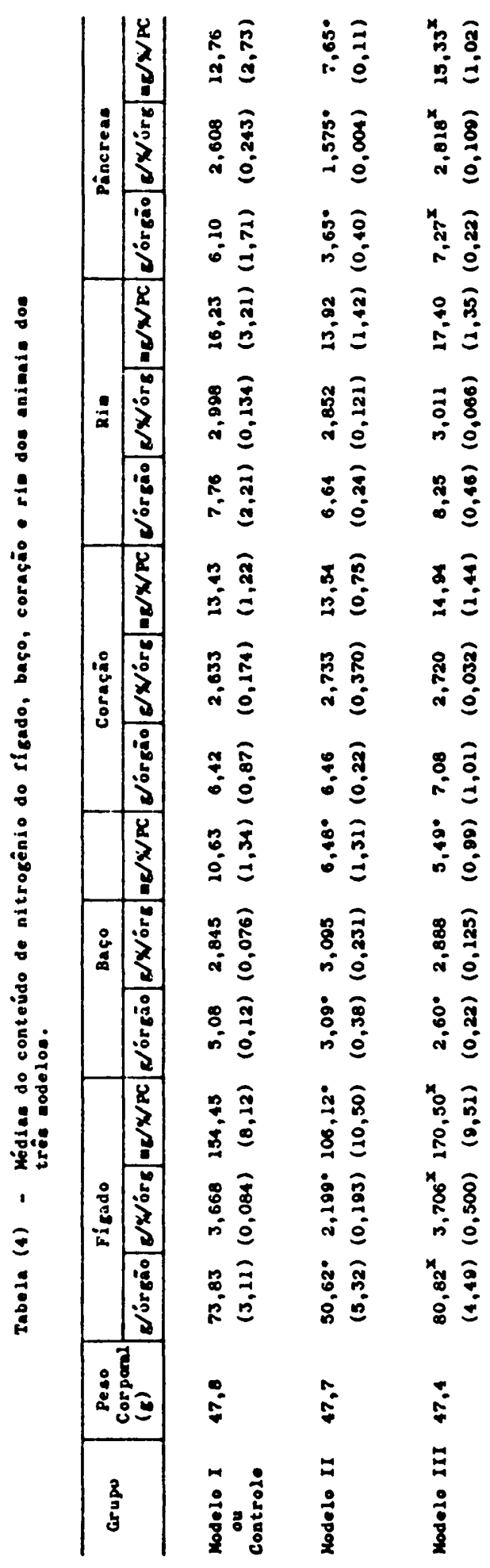


Tabela (5) - Média de lipideos totaie no fígado dos animais dos trêe modelos.

\begin{tabular}{|c|c|c|c|c|}
\hline Grupo & $\begin{array}{l}\text { Peso do } \\
\text { Il gado }\end{array}$ & $\mathcal{L} / \mathbb{V}_{\mathrm{f}} \mathbf{I}_{\text {gado }}$ & $\begin{array}{c}\text { egórgão to- } \\
\text { tal }\end{array}$ & $a_{g} / K /$ P.C. \\
\hline $\begin{array}{c}\text { Modelo I } \\
\text { ou } \\
\text { Controle }\end{array}$ & 2,013 & $\begin{array}{c}3,362 \\
(0,326)\end{array}$ & $\begin{array}{l}67,68 \\
(6,71)\end{array}$ & $\begin{array}{l}141,59 \\
(33,29)\end{array}$ \\
\hline Modelo II & 2,302 & $\begin{array}{r}5,537 \\
(0,943)\end{array}$ & $\begin{array}{l}127,46^{*} \\
(12,21)\end{array}$ & $\begin{array}{l}267,21 * \\
(37,33)\end{array}$ \\
\hline Modelo III & 2,067 & $\begin{array}{c}3,393^{x} \\
(0,572)\end{array}$ & $\begin{array}{l}70,13^{x} \\
(5,71)\end{array}$ & $\begin{array}{l}147,95^{x} \\
(29,18)\end{array}$ \\
\hline
\end{tabular}

- p $<0,01$ en relação ao controle

$x p<0,01$ en relação ao mode10 II

Tabela (6) - Porcentagem de água no fígado dos animais dos três modelos.

\begin{tabular}{c|c}
\hline Grupo & $\delta / 1 /$ gado \\
\hline
\end{tabular}

Mode 10 I

ou

70,68

Controle

$(0,02)$

Modelo II

$$
\begin{aligned}
& 72,00 \\
& (0,06)
\end{aligned}
$$

Modelo III

$$
69,92
$$

$$
(0,09)
$$


$\mathrm{Na}$ tabela (4) colocamos os resultados das dosagens de $\mathrm{N}$ nus órgãos, em gramas por órgão total, em g por $100 \mathrm{~g}$. do órgão e em nig por $100 \mathrm{~g}$ de peso corporal.

Tabela (6) - Porcentagem de água no fígado dos animais dos très modelos.

$\begin{array}{lc}\text { Grupo } & \text { g/\%!ligado } \\ \text { Modelo I } & 70.68 \\ \text { ou } & (0.02) \\ \text { Controle } & \\ \text { Modelo II } & 72,00 \\ & (0,06) \\ \text { Modelo III } & \\ . & 69,92 \\ & (0,09)\end{array}$

Como pudemos observar os órgãos dos animais do Modelo III, restrito em quantidade de alimentos, comportaram-se da mesma maneira que os do grupo com dieta balanceada, com exceçăo do baço que se atrofiou. apresentando uma diminuição de peso de $50 \%$ (tabela 3). Esta variação de peso acompanhou aproximadamente a diminuição de nitrogênio do baço. em relação ao do controle (tabela 4 ), o que parece indicar que a composição do órgão não se alterou.

Os animais em carència protéica apresentaram uma atrofia do baço e correspondente diminuição de nitrogênio. As maiores alterações ocorreram no fígado e no pâncreas nos animais do Modelo II, de restrição protéica. $O$ fígado aumentou de peso em relação ao dos animais do controle, mas esta alteração não foi significativa. Por outro lado. o órgão perdeu $32 \%$ dc nitrogênio e sofreu um acúmulo de $88 \%$ dos lipídeos totais, consequentemente podemos supor que algum outro constituinte do fígado tenha diminuido. Os resultados que encontramos para as fèmeas diferem dos encontrados para os machos (MATTOS, 1974), principalmente no grupo restrito em calorias. Neste grupo houve atrofia do figado e do pâncreas, embora o nitrogènio 
por unidade de peso do órgão não se alterasse.

HARRISON (1953) encontrou uma diferença no comportamento fisiológico do fígado das fêmeas e machos quando deixados em jejum. Verificou que com quatro dias de jejum, em ambos os sexos, o fígado perdeu água, proteína, glicogênio e fosfolipídeos. Após este período as fêmeas acumularam lipídeos e os machos glicogênio.

\section{CONCLUSÕES}

Os animais dos três grupos, embora apresentassem o mesmo peso, demonstraram as seguintes diferenças ponderais e bioquímicas:

1. Os animais em restrição calórica apresentaram atrofia do baço, embora a diminuição de peso tenha acompanhado a de nitrogênio.

2. O fígado e o pâncreas dos animais em deficiência proteīca não sofreram alteração de peso em relação ao controle, mas perderam nitrogênio e o fígado acumulou lipídeos.

3. O baço dos animais em carência protéica perdeu peso proporcionalmente a diminuição de nitrogênio.

MATTOS, L.U.; SALUM, M.J.L.; AMARAL, M.L.C.P. - Experimental protein-calorie malnutrition induced in early weaned female rats-Weight and biochemistry studies of some organs. Rev. Esc. Enf. USP, 9 (1) 35-47, 1975.

In order to study protein-calorie malnutrition two experimental models-calorie deficient and protein deficient models-have been produced in young female rats. When the mean weight of the rats of both models were $48 \mathrm{~g}$, the animals were killed. The spleen, liver. kidney, heart and pancreas were studied in relation to weight and nitrogen content, and compared to a control group of the same body weight. In the calorie deficient model only the spleen lost weight, but apparently its composition was unchanged. In the protein deficient model the weight of the liver and pancreas remained 
similar to those of the control group, but their composition was modified: both organs lost nitrugen and the liver accumulated fat.

\section{REFERENCIAS BIBLIOGRÁFICAS}

BARROWS, C.H. - The effect of dietary protein on the level of plasma cholinesterase of rats. J. Nutr., 66:515-530, 1958.

FUKUDA, M. \& SIBATANI, A. - Relation between the body weight and the average DNA content of liver nuclei in postnatal growth of the rat. Exp. Cell. Res., 4:236-238, 1953.

HARRISON, M.F. - Effect of starvation on the composition of the liver cell. Biochem. J., 55:204, 1953.

MATTOS, L.U. - Estudo ponderal e bioquímico de alguns órgãos de ratos submetidos à desnutrição protéica ou calórica após o desmame. (a publicar)

MENDES. C.B. \& WATERLOW. J.C. - The effect of a low protein diet. and reffeeding on the composition of liver and muscle in the wealing rat. Brit. J. Nutr., 12:74, 1958.

ROEDER, L.M. \& CHOW, B.F. - Influence of the dietary history of the test animals on responses in pharmacological and nutritional studies. Amer. J. Clin. Nutr., 24(8):947- , 1971.

STEPHAN, J.K. \& CHOW, B.F. - Growth of progeny from rats underfed during gestation only. Fed. Proc., 27:728, 1968 (abstr.). 